\title{
La publicidad y sus complejas relaciones con el discurso científico
}

\author{
Alfons Medina Cambrón I alfonsomc@blanquerna.url.uedu \\ Carolina Sorbías Morales | carolinasm0@blanquerna.url.edu \\ Sonia Ballano Macías | soniabm@blanquerna.url.edu \\ UNIVERSITAT RAMÓN LLULL
}

Resumen: Este artículo se aproxima desde un punto de vista teórico a la compleja relación que se establece a menudo entre publicidad y ciencia. Se denuncia la utilización de una idea estereotipada sobre el conocimiento científico como sinónimo de verdad absoluta. Esta concepción de la ciencia propia del positivismo y, por tanto, completamente superada por la teoría científica, se convierte en una fuente de argumentos sugerentes para una cierta radicalización del discurso postmoderno.

Palabras clave: Publicidad, discurso científico, conocimiento

Abstract: This essay approaches from a theory-based standpoint the complex relationship that usually links advertising and science. More specifically, it tries to expose the weaknesses in those stereotyped views that equate scientific knowledge with some kind of an absolute truth. Such a positivistic understanding of science - long superseded by present-time scientific theory- likely becomes a potential source of inspiration for the radicalization of the post-modern discourse.

Key words: Advertising, scientific speech, knowledge 


\section{Introducción}

Actimel con L. Cassei Immunitas, de Danone; Flora Pro-activ, de Unilever; Activia con Acti Regularis, de Danone; Crema Age Re-perfect Pro-Calcium, de L'Oréal; Essensis con ProNutris, de Danone; Jabón Johnson's con PH 5.5, etc. Como se observa, son múltiples las fórmulas publicitarias que las empresas adoptan para asociar sus productos a una determinada terminología científica. A veces el objetivo es, simplemente, el de otorgarles una apariencia científica. La publicidad en su conjunto, o al menos una parte de ella, posicionada como una de las formas masivas de comunicación más influyentes en el discurso social actual-, aun manteniéndose en los límites de una cierta corrección, está alimentando cada vez más la polarización estereotipada entre una idea de conocimiento que pertenece al pasado y una fuente de argumentos sugerentes para una cierta radicalización postmoderna.

A lo largo de este artículo pondremos de manifiesto este fenómeno, de carácter paradójico, que promueve el discurso mediático $y$, concretamente -aunque no de forma exclusiva-, la publicidad. La publicidad recurre, a menudo, a un concepto y una concepción de ciencia que han sido ampliamente superados en la discusión científica. Se trata de una especie de vuelta al mito o de 'mito reencontrado', en palabras de Vattimo (Vattimo, 1990: 111-163) ${ }^{1}$. No obstante, todo investigador/a es consciente de la dificultad que comportaría hoy en día hablar de verdades absolutas, de superioridad total del discurso científico, de una concepción de ciencia adoptada desde posicionamientos prácticamente místico-religiosos. De la misma manera, debemos ser conscientes de la dificultad que posee el discurso publicitario para crear un mensaje provisional, parcial, abierto a matices.

La crítica postmoderna, desde su origen, se centra en la negación, por otra parte evidente, de la existencia de una idea de conocimiento como verdad absoluta. La teoría postmoderna refuta la pretendida superioridad del discurso científico arguyendo la desaparición de los metarrelatos, defendiendo que no existe relato explicativo que posea un carácter superior a otros, invalidando el sentido de la noción de ciencia, relativizando todo conocimiento científico.

En este contexto, cobra protagonismo el discurso mediático, un texto sin fin, un magazín interminable, tal y como lo define Miquel Treserras (Treserras, 2005: 58) ${ }^{2}$. Un discurso condenado -por su propia naturaleza- a convertirse en un collage de construcciones

\footnotetext{
1 Vattimo utiliza el concepto de 'mito reencontrado' para hacer referencia a "un momento de desmitificación de la desmitificación" que "se puede considerar como el momento en que justamente se pasa de lo moderno a lo posmoderno", como "el final de la utopía revolucionaria de los años sesenta: a causa de la explosión del sistema, de la impensabilidad de la historia como curso unitario". Nosotros, sin embargo, utilizamos este término para referirnos al discurso mediático como un reencuentro, tal vez involuntario, con el mito del positivismo, con la centralidad, con la totalidad de la ciencia.

2 "(...) Signos lingüísticos que se combinan según las reglas de una gramática precisa -la gramática audiovisual-, forman unidades de sentido que superan la extensión de un producto determinado y construyen frases que se enlazan con las siguientes y con las anteriores. En el mismo sentido que las proposiciones y los párrafos, los programas son subtextos que se integran en un texto más general, único, que toma forma de collage que se unifica en un magazín que no se acaba".
} 
estereotipadas, de informaciones y mensajes caracterizados por su inmediatez, su fugacidad, su eficacia total. Se trata, paradójicamente, de un discurso interminable hecho de productos acabados, cerrados, incapaces de asumir un discurso en términos de probabilidad. $Y$ es, en este sentido, que sostenemos que el discurso mediático alimenta una noción de ciencia que ha quedado desfasada; pues no existe ciencia, en términos actuales, que pueda desligarse del concepto de provisionalidad.

De este modo, el discurso mediático (que a menudo se considera como discurso propio de la postmodernidad, propio de la era de la fragmentación, de la descontextualización, del relativismo, de la multiplicidad de perspectivas) alimenta, al mismo tiempo, una concepción totalitaria de la ciencia y del concepto científico propios del positivismo de finales del siglo XVIII y principios del XIX:

En el grado en que la realidad dada es científicamente comprendida y transformada, en el grado en el que la sociedad se hace industrial y tecnológica, el positivismo halla en la sociedad el medio para la realización (y la ratificación) de sus conceptos (Marcuse, 1994: 199).

En este artículo, no pretendemos poner de manifiesto la utilización de conceptos o terminología científica en la publicidad para anunciar un determinado producto -ya sea de una manera más o menos adecuada o directamente incurriendo en estrategias que se alejan totalmente del rigor científico (Campanario, Moya y Otero, 2001). Aquello que realmente nos interesa, es denunciar la relación compleja que a menudo se establece entre publicidad y ciencia; es decir, analizar la utilización de una determinada idea (por parte de la publicidad, pero también del discurso mediático, en general) de lo que es el conocimiento científico. Así, analizaremos algunas de las principales consecuencias que este hecho plantea. Entre otras, cabe destacar la incidencia en un cierto estereotipo de la noción de ciencia que retroalimenta -pese a no ser, evidentemente su objetivo- una crítica cada vez más radical del discurso científico, del discurso que debería ofrecer una cierta estabilidad, rigurosidad y fiabilidad sobre todo objeto de estudio.

Con esta finalidad, partiremos de la crisis del pensamiento científico-positivista, profundizaremos en el relativismo y su vinculación con las teorías de la postmodernidad y, finalmente, veremos la relación que se establece entre los medios de comunicación y la transmisión de una idea de ciencia estereotipada y completamente desfasada.

\section{La discusión en torno a la creación del conocimiento científico y la crisis del pensamiento científico-positivista}

Una de las discusiones más relevantes de la historia del conocimiento científico viene dada por su voluntad de alcanzar una cierta objetividad, entendida como una de las características principales que lo distinguen de otras formas de argumentación o conocimiento. En este sentido, el nacimiento de las ciencias sociales sentó las bases para la discusión sobre el método y la posibilidad (o no) por parte de las ciencias sociales, de producir conocimiento de 
esta naturaleza. Es significativo, por tanto, el hecho de que, desde su proceso de institucionalización, las ciencias sociales hayan vivido en un complejo de inferioridad. Para entender cómo se ha llegado a esta situación conviene explicar, aunque de manera sintética, las polémicas en torno a la creación del conocimiento científico y la consolidación de una determinada idea de ciencia durante buena parte del siglo XX.

Los filósofos de la ciencia se remontan, para las discusiones sobre el método científico, a los textos de Aristóteles, pero cabe destacar que estas no se generalizarán de una manera plena hasta bien entrado el siglo XX, impulsadas por el desarrollo de la metodología de la ciencia (D’agostini, 2000; Echeverría, 1999; Losee, 1997; Mardones y Arsua, 1983; Merton, 1985; Popper, 1985; Wartofsky, 1987). En este sentido, sería necesario remontarnos a los pensadores clásicos que en los últimos dos mil años han ido colocando los cimientos de lo que actualmente consideramos como conocimiento científico; trazando una línea desde Aristóteles, pasando por Galileo, Descartes, Bacon o Newton hasta llegar al siglo XIX, donde se institucionalizan las disciplinas académicas. No obstante, por cuestiones de espacio y tiempo, consideramos oportuno partir de la discusión planteada a finales del siglo XIX y principios del $\mathrm{XX}$, momento en que empieza a gestarse el debate sobre la crisis del pensamiento positivista coincidiendo con la consolidación de las ciencias sociales.

En primer lugar, es necesario poner de manifiesto que, en el ámbito de las ciencias sociales, no se ha llegado, por el momento, a un consenso en relación a la fundamentación científica. Desde el siglo XIX encontramos una división entre los partidarios de que el conocimiento social se ajuste al canon de las ciencias físicas y naturales, y aquellos que defienden la búsqueda de una vía original, propia del conocimiento social, sin que este pueda ser considerado en un plano de inferioridad. Simplificando las diferentes posturas, podemos distinguir un modelo de explicación científica que sigue el canon de las ciencias naturales y un modelo que incide en las características propias que poseen los fenómenos sociales y la manera en que podemos llegar a comprenderlos. De este modo, a lo largo del siglo XX, los partidarios de la primera opción tenderán a reducir las argumentaciones a demostraciones deductivas mientras que, los partidarios de la segunda, intentarán que sus argumentaciones tengan igualmente un cariz científico, pero sin caer en la imitación del modelo de las ciencias físicas y naturales.

Pese a esta falta de consenso a la que hemos hecho referencia, el positivismo clásico ha ejercido una notable influencia en las ciencias sociales desde su nacimiento hasta la actualidad. El término de ciencia positiva presenta un conocimiento científico que tiene su fundamento último en la comprobación de unas hipótesis que deben contrastarse con la fiel observación de la realidad. Este enfoque sostiene que, para alcanzar la objetividad a partir de la aprehensión de las estructuras de la realidad, es necesario que el investigador no se deje "contaminar" por los fenómenos del mundo social. Se trata, por tanto, de una concepción de las ciencias sociales en el primero de los sentidos que hemos apuntado: como modelo de explicación científica que sigue el canon de las ciencias físicas y naturales. Para ello, se adoptará la lógica formal matemática como instrumento más adecuado para 
establecer leyes generales causales que puedan ofrecer una explicación rigurosa de los fenómenos sociales y que, incluso, puedan llevar a los investigadores a predecirlos. Esta lógica positivista defenderá que la ciencia es la única capacitada para ofrecer un conocimiento verdadero y para resolver todas las cuestiones teóricas y prácticas relativas a la vida social (Busquet, Medina y Sort, 2006). Por tanto, según esta concepción, el científico es el único que está en posesión de la verdad.

Sin embargo, el conocimiento científico es tan sólo una de las diferentes formas de aproximación y comprensión de la realidad social. Históricamente, la religión y los mitos han cumplido un papel central en la explicación de los fenómenos sociales. Con la llegada de la Modernidad y el proceso de racionalización, la ciencia -basándose en la razón teórica y mediante la observación empírica- irá desplazando, progresivamente, a las explicaciones religiosas o animistas. No estamos diciendo con ello que las explicaciones científicas hayan substituido a las explicaciones míticas o religiosas, sino que no todas las explicaciones sobre la realidad pueden tener el mismo valor o fundamentación epistemológica. Una argumentación de tipo científico debe asumir unas determinadas premisas que implican distanciarse de otros discursos de carácter literario, mítico o religioso. En este sentido, podemos decir que la ciencia es, en definitiva, un conjunto de argumentaciones y teorías que tratan de ofrecer explicaciones sobre el mundo físico o social con unas condiciones concretas de rigor teórico y metodológico, sumados a un tratamiento exhaustivo de los datos.

Será el cuestionamiento de las verdades científicas como verdades absolutas y la supuesta infalibilidad de su método lo que hará entrar en juego otras maneras de explicar la realidad, tanto o más válidas. La crítica al positivismo, por parte de las posturas hermeneúticas o compresivistas, será de vital importancia para situar sobre el terreno otras posturas de análisis no exclusivamente positivistas. Aún así, durante toda la segunda mitad del siglo XX, reavivará continuamente el debate sobre si lo que hacemos es objetivo en el sentido positivista, objetivo en otro sentido (cómo intentarán demostrar las posiciones constructivistas), meramente subjetivo (y si esto representará algún problema a la hora de hacer ciencia), o bien intersubjetivo. En este contexto, ¿podemos generar un conocimiento verdadero sobre la realidad? ¿Es imposible establecer verdades generalizables? La posición dominante en el discurso científico sostiene que es posible, aunque sin que ello comporte establecer verdades absolutas inmanentes e incuestionables.

No obstante, como avanzábamos en la introducción, el concepto ciencia vive actualmente inmerso en una paradoja. Por un lado, todavía mantiene ese aire de solemnidad y de prestigio que le permite validar cualquier tipo de trabajo, investigación, noticia o hecho acontecido. Expresiones del tipo "estudios científicos demuestran...", "tiene valor científico..." o "científicos afirman que..." siguen otorgando un sentido mucho más riguroso a aquello que se está explicando, describiendo o publicitando. $Y$, de hecho, el conocimiento científico, en teoría, debería tener esta función. Sin embargo, en el siguiente apartado pondremos de manifiesto el intento, por parte de la crítica postmoderna, de desenmascarar la pretendida superioridad del discurso científico con respecto a cualquier otro discurso o relato. Una visión 
de la ciencia que, por otra parte, pertenece a un primer positivismo y que ha sido, como hemos argumentado a lo largo de este apartado, totalmente superada por el debate científico.

En realidad, la teoría postmoderna ha extremado las críticas hacia el discurso científico sin tener en cuenta las visiones que, desde dentro, han puesto de manifiesto que, pese a continuar siendo necesario, no puede considerarse como un discurso proveedor de verdades absolutas e inmanentes.

\section{La crítica postmoderna al discurso científico}

Ya hemos señalado de qué manera la evolución de la historia del método científico nos transporta, desde la segunda mitad del XX a las primeras propuestas de tipo relativista. Desde la filosofía y la metodología de la ciencia se iniciará una manera de pensar que hará entrar en crisis la idea de ciencia aceptada hasta el momento. Los trabajos de Kuhn (1995, 1996), Feyerabend (1982, 1994) o posteriormente Lyotard (1993, 1996) o Vattimo (1990, 1998) y Rorty (2000) constituirán algunos de los ataques más contundentes a la noción de ciencia (Busquet, Medina y Sort, 2006).

No obstante, el relativismo metodológico y el postmodernismo no deben considerarse corrientes que surgen de manera espontánea, sino fruto de la evolución propia de la discusión y el debate continuo en el marco del discurso científico. En este sentido, cabe señalar -en relación a la metodología de la ciencia- que en el campo de la estética ya se habían iniciado este tipo de debates hacía unas décadas. Las mismas tesis de Feyerabend, por ejemplo, no se pueden entender sin el concepto de falsación popperiano ${ }^{3}$ o $\sin$ la inconmensurabilidad de las teorías científicas de Kuhn. Lo que sí constituirá una novedad es el éxito que tendrán estas teorías y su difusión por muchos departamentos universitarios desde finales de los setenta y principios de los ochenta del siglo pasado. Un hecho motivado, en gran parte, por la edición de La Condición Postmoderna, de J. F. Lyotard, que será un claro desencadenante de los debates y discusiones más importantes de las últimas dos décadas.

La réplica a los posicionamientos de Lyotard y en general al discurso postmoderno, encontró en Habermas $(1987,1993)$-durante la década de los ochenta y los noventa- su figura principal $^{4}$. Habermas afirma en el conjunto de su obra que la Modernidad es un proyecto

\footnotetext{
${ }^{3}$ Conviene recordar que la falsación popperiana introduce un elemento de provisionalidad en una idea absoluta, cerrada y hermética de aquello que era considerado ciencia. En este sentido, Habermas (1987, 1998, 1999) o Wellmer (1994) estarían de acuerdo en que "el contenido de un consenso racional es verdadero mientras no se ponga en duda tal consenso. Lo que hace Wellmer, en definitiva, es aplicar el principio de falsabilidad popperiano a la idea de consenso racional. Garantizar la racionalidad discursiva no quiere decir hallar la verdad o que exista un consenso general en todo. Equivale a presuponer las condiciones que garantizan que cualquier disputa sobre pretensiones de validez será resuelta por la vía de los argumentos" (Medina, 2004: 149).

${ }^{4}$ La racionalidad, heredada del proyecto de la Modernidad, que Habermas intenta salvar y reconducir ante los ataques que recibe desde diversos frentes, se basará en la capacidad de los sujetos de comunicarse y actuar.
} 
abierto e inacabado, mientras que Lyotard, en cambio, la considera un proyecto agotado, con todas las consecuencias políticas que comporta este juicio de valor, es decir, el replanteamiento de los ideales de la Ilustración.

La obra de Lyotard se centrará en la crítica radical a las principales aportaciones de la Modernidad: la idea del sujeto, la razón asociada a la idea de la búsqueda de la verdad y la idea del bien y la desconfianza en los grandes discursos globalizadores y explicativos de la sociedad. El saber científico, por lo tanto, será considerado una clase de discurso más. Como consecuencia, no tendrá sentido hablar de legitimación de un discurso. Cualquier tipo de pretensión de validez en el conocimiento no tendrá razón de ser:

Este planteamiento (...) no tiene la pretensión de ser original, ni siquiera de ser verdadero. Lo que se le exige a una hipótesis de trabajo es una gran capacidad discriminadora. (...) No es preciso, por tanto, concederle un valor provisional con respecto a la realidad, sino estratégico con respecto a la cuestión planteada. Con todo, su credibilidad es considerable (Lyotard, 1993: 21).

Un elemento central en La Condición Postmoderna, de J. F. Lyotard, es la crítica a los metarrelatos, que se puede interpretar como una crítica al discurso emancipador y de progreso a partir de la ilustración, y supone una carga de profundidad epistemológica mucho más grave (incluso en relación a la idea misma de racionalidad). Esta es, precisamente, una de las peores acusaciones que pesan hoy sobre el postmodernismo: haber legitimado un relativismo extremo y autodestructivo en todos los ámbitos del saber humano (no sólo la moral). Aunque sus bases filosóficas son muy anteriores, este relativismo ya estaba expuesto, a nivel epistemológico, en las teorías de Feyerabend, tanto en la obra Contra el Método, como en La ciencia en una sociedad libre o, más adelante, también sería expuesto en la inconmensurabilidad de las teorías planteada por Kuhn (tras haber elaborado su teoría sobre la estructura de las revoluciones científicas).

En este sentido, creemos que la deriva postmoderna ha afectado notablemente a los medios de comunicación en general. Del mismo modo, constatamos que la propia evolución de los medios de comunicación también ha influido en algunas características postmodernas. No es casual que Vattimo considere que el nacimiento de la crisis de un conocimiento unitario $-y$, por tanto, totalmente fragmentario y provisional- sea a partir del auge de los medios de comunicación de masas en las primeras décadas del siglo XX. Para Vattimo, la expansión de los medios de comunicación generará una gran diversificación de fuentes de información y de opiniones. De este modo, se puede provocar una pérdida de "objetividad", fruto de entender que no existe una verdad o bien que todo es mentira. Esta idea está en total sintonía con la desaparición de los metarrelatos científicos, antes apuntada, y la consiguiente pérdida de objetividad y verdad, idea central de un determinado tipo de ciencia (Vattimo, 1990). En este sentido, Lyotard escribe La Condición Postmoderna intuyendo parte de las consecuencias que para las metanarrativas tendrá la revolución de las tecnologías de la información y la comunicación (Lyotard, 1993). 
Eco, en su obra Los límites de la interpretación, intenta limitar la deriva postmoderna que implica "abrir" la obra a cualquier posible interpretación, como él mismo había hecho en un principio. De este modo critica las consecuencias que, para la interpretación de una obra, tiene el deconstruccionismo de autores como Derrida, o el "pragmatismo" extremo de autores como R. Rorty. Eco nos viene a decir, por tanto, que no puede invocarse una teoría de la interpretación como deriva y deconstrucción, porque existe un sentido en los textos o bien hay muchos, pero no se puede decir que no haya ninguno o que todos sean igualmente válidos (Eco, 1991).

Por otra parte, Ferran Sàez, en su obra Comunicación y Argumentación, manifiesta de manera muy clara que la práctica comunicativa necesita encontrar un camino intermedio entre las demostraciones deductivas que implican establecer relaciones causales (totalmente imposible de establecer en las ciencias sociales e incluso se duda que también puedan llevarse a cabo en las denominadas ciencias duras) y la mera retórica persuasiva (Sàez, 2003). ¿En qué basamos los criterios de verosimilitud que deben establecerse en el ámbito de la comunicación? La llave para ofrecer ese criterio de "objetividad" o de verosimilitud está en la fuerza de nuestros argumentos.

En definitiva, y desde posiciones totalmente antagónicas, a partir de la observación de la realidad, diferentes teóricos sostienen que estamos en la modernidad, en una segunda modernidad, en una modernidad radicalizada o en una sociedad postmoderna. Es evidente que todos estamos observando la misma realidad $y$ en función de los diferentes posicionamientos teóricos ponemos el énfasis explicativo en unos fenómenos o bien en otros.

\section{Los medios de comunicación y la transmisión de una idea de ciencia estereotipada: la publicidad}

Tal y como hemos destacado en el apartado anterior, el conocimiento científico es un conjunto de argumentaciones y teorías que, siguiendo un determinado método, aplicado de forma rigurosa, es capaz de ofrecer descripciones o explicaciones sobre la realidad social. Seguidamente, pasaremos a describir qué idea de conocimiento científico toma la publicidad y cómo esta retroalimenta el discurso postmoderno que hemos sintetizado en el apartado anterior.

En un mercado altamente diversificado y con numerosos productos similares entre sí, una de las estrategias clave de la publicidad es posicionar, cada producto o servicio, en la mente del consumidor o, como cita Moliné, "construirles una personalidad que les de un lugar distinto en el mercado en relación con sus consumidores" (Moliné, 1996: 84). Una forma de aplicar esta estrategia es, sin duda, asociar el producto a afirmaciones procedentes de una fuente creíble, como puede ser el discurso científico. En otras ocasiones, se hace mediante una "innovación genérica a la ciencia, sin mayor profundidad o justificación [...] o se usan 
conceptos inexistentes que crean la impresión de una explicación científica o de un razonamiento sólido" (Campanario, Moya y Otero, 2001: 48).

En definitiva, la ciencia y la publicidad se encuentran relacionadas cuando se asocia el discurso científico a un artículo publicitado para dotarlo de una fuente de autoridad y de fiabilidad. Esto, supuestamente, garantiza la calidad de aquello que se anuncia. No obstante, la publicidad abusa del uso de una terminología que mimetiza con gran eficacia el lenguaje científico, pero a la vez, tal y como hemos argumentado a lo largo de este artículo, muestra una gran indiferencia y desprecio por la ciencia al transmitir una concepción de 'verdad absoluta' completamente desfasada, en el discurso realmente científico, por la noción de provisionalidad.

Tal y como afirma Ramiro, "el paradigma de productos de consumo investidos de certeza por la ciencia son los alimentos funcionales y los productos de belleza" (Ramiro, 2007). Así, existe una gran variedad de productos utilizan conceptos pseudocientíficos como reclamo publicitario, como por ejemplo Actimel con L. Cassei Immunitas, de Danone. Según la web del grupo Danone,

\begin{abstract}
Actimel es uno de los productos más innovadores de Danone en el campo de la salud. Además de los beneficios tradicionales del yoghourt, cuenta con un fermento exclusivo, L.Casei DN 114001. Esta exclusiva bacteria láctica, desarrollada por Danone, ayuda a reforzar las defensas del organismo. Un estudio en niños que toman Actimel ha demostrado que tienen menos absentismo escolar (Danone, 2007).
\end{abstract}

Otros ejemplos son Activia con Acti Regularis, también de Danone, en dónde "su exclusivo Bifidobacterium DN 173-010 contribuye a renovar tu esencial flora intestinal" (Danone, 2007), Crema Age Re-perfect Pro-Calcium, de L'Oréal, siendo el Pro-Calcium "un complejo específico bioasimilable por la piel", (L'Oréal, 2007), Essensis de Danone, con ProNutris, o Retinol Anti-Celullite de ROC, que garantiza unos resultados visibles de hasta $5 \mathrm{~cm}$, "resultados obtenidos según el contorno de la talla, evaluación clínica, 49 mujeres, aplicación cotidiana durante 12 semanas, resultados medios 0,6 cm" (Johnson \& Johnson Consumer, 2007). Pero, ¿podemos considerar que 49 mujeres constituyen una muestra realmente representativa del conjunto de mujeres españolas, para poder garantizar unos resultados anticelulíticos tan visibles en unas semanas? Si bien la publicidad recurre habitualmente al discurso científico para dotar de credibilidad a los anuncios y para llamar la atención a los consumidores, la mayor parte de las veces no lo hace de manera adecuada o no proporciona suficiente información al consumidor. Según afirman Campanario, Moya y Otero,

(...) no es fácil explicar de manera clara en un breve anuncio, los mecanismos científicos o técnicos de actuación de un productos y las cualidades que lo hacen bueno o que garantizan su eficacia [...], es más fácil invocar a la ciencia o a la investigación de forma genérica, o crear la impresión de que se ha presentado una argumentación científica y rigurosa, cuando en realidad no es así (Campanario, Moya y Otero, 2001: 55).

En este sentido, la publicidad parece adoptar la fórmula Razón=Verdad=Realidad, promulgada por Marcuse. Al actuar de esta manera, la publicidad incurre en un descrédito de 
la ciencia o del conocimiento científico. Un descrédito que, además de provocar escepticismo en el consumidor, alimenta la crítica realizada por el postmodernismo a la concepción de ciencia como sinónimo de verdad absoluta. Es así como se produce la gran paradoja: los medios de comunicación, erigidos a menudo como bandera de la condición postmoderna de las sociedades actuales, se convierten en resignificadores de una concepción totalmente desfasada del papel de la ciencia y de la naturaleza del conocimiento científico:

(..) El hecho de que un sustantivo específico sea unido casi siempre con los mismos adjetivos y atributos "explicativos", convierte la frase en una fórmula hipnótica que, infinitamente repetida, fija el significado en la mente del receptor. (...) Todas tienen en común un alejamiento y contracción de la sintaxis que limita el desarrollo del significado, creando imágenes fijas que se imponen a sí mismas con su abrumadora y petrificada concreción. Es la conocida técnica de la industria de la publicidad (Marcuse, 1994: 121).

Como vemos, esta característica de la publicidad, como discurso mediático que utiliza a la ciencia para ofrecer fiabilidad total, certeza absoluta, poco tiene que ver con el discurso postmoderno que, en palabras de Lyotard "fortalece nuestra capacidad de soportar lo inconmesurable" (Lyotard, 1993: 11), muy al contrario, alimenta una concepción mística de la ciencia como progreso y como verdad en términos absolutos; una ciencia que tranquiliza y que reclama, por tanto, una fe absoluta por parte -en el caso de la publicidad- de los consumidores.

Sin embargo, la fórmula que denuncia y critica Marcuse, Razón=Verdad=Realidad, no sólo está presente en el discurso publicitario, se puede hacer extensible a la totalidad del discurso mediático, puesto que las televisiones, entre otras productos, nos ofrecen desde hace tiempo diferente programas de entretenimiento disfrazados de periodismo de investigación (pretendidamente científica) cuando, en realidad, son una mezcla de entretenimiento y esoterismo o pseudo-investigación. En este sentido, a menudo, la televisión, la radio o la prensa reclaman la participación de científicos que avalen, desde su experiencia, informaciones $u$ opiniones que sostiene, fabrica o comunica el propio medio. Como consecuencia, se alimenta -del mismo modo que en el caso de la publicidad- la crítica al discurso científico desde las teorías filosóficas de la postmodernidad.

\footnotetext{
(...) ¿qué hacen los científicos en la televisión, entrevistados en los periódicos, después de algún "descubrimiento"? Cuentan una epopeya de un saber perfectamente no-épico. (...) se refiere a la relación del saber científico con el saber «popular», o lo que queda de éste. (...) la ciencia puede presentarse como epopeya (Lyotard, 1993: 57).
}

Sin embargo, pese a que mediante este artículo se procura denunciar una consecuencia no pretendida por parte del discurso mediático, no compartimos la crítica que generalmente recae sobre los medios de comunicación como inoculadores de los temas, principios y valores que una minoría dominante pretende configurar en la mente del resto de los ciudadanos. Partimos de una concepción del receptor como co-significador de estos mensajes; por tanto, de un receptor activo, capacitado, que interpreta el discurso mediático y que es capaz de elaborar una crítica razonada al respecto. No obstante, esta capacidad se puede ir 
debilitando cada vez más si acaba imperando el "todo vale" y la fragmentación total de los discursos y las argumentaciones.

\section{Conclusiones}

En este artículo hemos mostrado cómo la publicidad y los medios de comunicación en general, asocian a su discurso persuasivo una determinada idea de ciencia basada en un conocimiento verdadero y absoluto. Es comprensible que la publicidad intente ofrecer certezas y verdades asociadas a un determinado producto. Sin embargo, esta idea de conocimiento científico a la que a menudo se refieren está ampliamente superada en la discusión científica actual.

Gracias al debate y la discusión teórica y metodológica desarrollada a lo largo del siglo XX, la concepción predominante en el discurso científico ha desbancado al positivismo (que defendía una idea absoluta de verdad que le permitía conocer e incluso predecir cualquier situación social), adoptando una concepción que aboga por el conocimiento de carácter provisional, parcial y probabilístico, pero que mantiene la posibilidad de conocer científicamente la realidad social.

Sin embargo, algunas corrientes científicas que no se conforman con el ejercicio de rectificación y matización a que se somete la misma ciencia, optan por radicalizan la crítica al conocimiento. En este sentido, al postmodernismo no le bastará con una aceptación de la falibilidad del conocimiento científico y de su provisionalidad, sino que extremará dicha crítica hasta proclamar la imposibilidad de realizar discursos "pretendidamente superiores" y explicativos de la sociedad. Negando, por tanto, la posibilidad de establecer metarrelatos (ya que no se podrá constituir una jerarquía epistémica que sitúe a unos por encima de otros).

En este artículo sintetizamos la evolución del discurso científico desde el momento en que se realiza la crítica a una ciencia positivista hasta llegar a la situación actual. Podemos situar esta última en un contexto de cierto pluralismo metodológico que huye de una concepción de ciencia como unidad, como intérprete exclusiva de la realidad social. No obstante, es importante hacer notar que parte de la crítica postmoderna a lo que entendemos como ciencia no tiene en cuenta este proceso interno de reflexión. Esto se debe, principalmente, a que la noción positivista de ciencia se ha incorporado y estereotipado en gran parte de los medios de comunicación, que se convierten, de este modo, en el principal difusor de este discurso contradictorio, paradójico.

Ante esta situación, únicamente podemos ofrecer un acercamiento al tema mediante una reflexión sobre la incongruente situación (en relación al tema tratado) en la que se encuentra la publicidad y los medios de comunicación en general. Ya que, si bien es cierto que el discurso científico se adopta de una manera instrumental, es decir, para hacer más eficaz la venta de un determinado producto; la publicidad se convierte, en parte, en corresponsable de su descrédito. Tal vez deberíamos preguntarnos si este concepto desfasado de ciencia 
continuará siendo útil a la publicidad en un futuro próximo. Una de las consecuencias de todo ello es que al final resulte extremadamente difícil distinguir la alusión a la verosimilitud, a la creatividad o a la ironía de la simple impostura o falsedad. 


\section{REFERENCI AS BI BLI OGRÁFI CAS}

AdoRno, T.W et al. (1973): La disputa del positivismo en la sociología alemana. Barcelona, Grijalbo.

BECK, U. (1998): ¿Qué es la globalización? Falacias del globalismo, respuestas a la Globalización. Barcelona, Paidós.

BusqueT, J.; MEDINA, A.; SORT, J. (2006): La recerca en comunicació. Què hem De Saber? Quins passos hem de seguir?. Barcelona, UOC.

CAMPANARIO, J.; MOYA, A.; OTERO, J. C. (2001): "Invocaciones y usos Inadecuados de la ciencia en la publicidad", en Enseñanza de las Ciencias, no 19, pp. 4556.

Comte, A. (1982): Discurs sobre l'esperit positiu precedit de les dues primeres Lliçons del Curs de Filosofia Positiva. Barcelona, Laia.

D'Agostini, F. (2000): Analíticos y Continentales. Guía de la Filosofía de los Últimos treinta años. Madrid, Cátedra.

DANONE, (2007): [En línea]. Barcelona, en http://www.danone.es (consultado: 25/09/2007).

ECHEVERRÍA, J. (1999); Introducción a la Metodología de la Ciencia. La filosofía de La Ciencia en el siglo XX. Madrid, Cátedra.

Eco, U. (1991): Els límits de la interpretació. Barcelona, Destino.

Feyerabend, P. (1994): Contra el Método. Barcelona, Planeta-Agostini.

FeYerabend, P. (1982): La ciencia en una sociedad libre. Madrid, Siglo XXI.

HABERMAS, J. (1987): La teoría de la acción comunicativa. Madrid, Taurus.

Habermas, J. (1993): El discurso filosófico de la modernidad. Madrid, Taurus.

Habermas, J. (1998): Facticidad y validez. Madrid, Trotta.

HABERMAS, J. (1999): La inclusion del otro. Barcelona, Paidós Básica.

JOHNSON \& JOHNSON CONSUMER, (2007): [En línea]. Paris, en http://www.roc.fr (consultado: 25/09/2007).

KuHN, T.S. (1995): La Estructura de las Revoluciones Científicas. México, FCE.

KUHN, T.S. (1996): ¿Qué son las revoluciones científicas? Y otros ensayos. Barcelona, Paidós ICE-UAB.

L'ORÉAL, (2007): [En línea]. Madrid, en http://www.loreal.es (consultado: 25/09/2007).

LOSEE, J. (1997). Introducción histórica a la filosofía de la ciencia. Madrid, Alianza Universidad.

LYOTARD, J.F. (1996): ¿Por qué filosofar?. Barcelona, Paidós/ICE-UAB.

LYOTARD, (1993): La condición postmoderna. Barcelona, Planeta-Agostini.

MARCUSE, H. (1994): El hombre unidimensional. Barcelona, Ariel. 
Mardones, J.M, Arsua, N. (1983): Filosofía de las Ciencias Humanas y Sociales. Barcelona, Fontamara.

MedinA, A. (2004): "D'una objectivitat provisional a una ètica universal", en Tripodos (2004), n¹6, pp. 141-153.

Moliné, M. (1996): La Comunicación activa, Publicidad sólida. Bilbao, Deusto.

POPPER, K.R. (1962): La Lógica de la Investigación Científica. Madrid, Tecnos.

POPPER, K.R (1985): El coneixement objectiu. Barcelona, Edicions 62.

Ramiro, P. (2007): ¿Con Bífidus Activo? Lo compro. [En línea]. Madrid: Periódico Quincenal de actualidad crítica Diagonal Web, en http://demos.dabne.net/ diagonal (consultado: 23/09/2007).

RORTY, R. Verdad y progreso. Barcelona, Paidós Básica.

SABATÉ, J. (1997): La publicitat. Barcelona, Pòrtic.

SÀEZ, F. (2003): Comunicación y argumentación. Barcelona, Papers d’Estudi.

TRESSERRAS, M. (2006): La ciutat de risc. El prodigi de la televisió i altres Tecnologies. Barcelona, Papers d'estudi.

VATtimo, G. (1990): La Sociedad Transparente. Barcelona, ICE/UAB.

Weber, M. (1992): Economía y Sociedad. Esbozo de sociología comprensiva. Buenos Aires, Fondo de Cultura Económica.

[Recibido: 28-09-2007. Aceptado: 25-10-2007] 